\section{Kidney \\ Blood Pressure Research}

\title{
Extracellular Volume Overload and Increased Vasoconstriction in Patients With Recurrent Intradialytic Hypertension
}

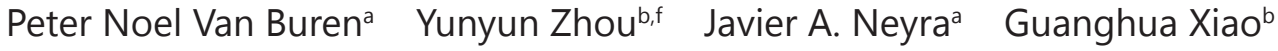 \\ Wanpen Vongpatanasinc Jula Inrig d,e Robert Toto ${ }^{\mathrm{a}}$ \\ aUniversity of Texas Southwestern Medical Center, Department of Internal Medicine, Division of \\ Nephrology, Dallas, TX; bUniversity of Texas Southwestern Medical Center Department of Clinical \\ Sciences, Quantitative Biomedical Research Center, Dallas, TX; CUniversity of Texas Southwestern \\ Medical Center, Department of Internal Medicine, Division of Cardiology, Dallas, TX; 'Duke University

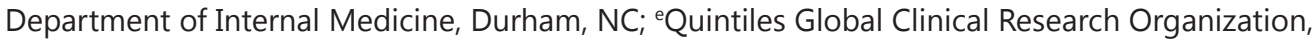 \\ Department of Medicine, Morrisville, NC; fUniversity of Mississippi Medical Center, Department of Data \\ Science, Jackson, MS, USA
}

\section{Key Words}

Intradialytic Hypertension - Bioimpedance Spectroscopy • Extracellular Volume - Peripheral Resistance • Endothelin-1 $\bullet$ Hemodialysis

\begin{abstract}
Background/Aims: Intradialytic hypertension (IH) occurs frequently in some hemodialysis patients and increases mortality risk. We simultaneously compared pre-dialysis, post-dialysis and changes in extracellular volume and hemodynamics in recurrent IH patients and controls. Methods: We performed a case-control study among prevalent hemodialysis patients with recurrent IH and hypertensive hemodialysis controls. We used bioimpedance spectroscopy and impedance cardiography to compare pre-dialysis, post-dialysis, and intradialytic change in total body water (TBW) and extracellular water (ECW), as well as cardiac index (CI) and total peripheral resistance index (TPRI). Results: The ECW/TBW was $0.453(0.05)$ pre-dialysis and $0.427(0.04)$ post-dialysis in controls vs. $0.478(0.03)$ and $0.461(0.03)$ in IH patients $(p=0.01$ post-dialysis). The ECW/TBW change was -0.027 (0.03) in controls and $-0.013(0.02)$ in IH patients $(p=0.1)$. In controls, pre- and post-dialysis TPRI were 3254 (994) and 2469 (529) dynes $/ \mathrm{sec} / \mathrm{cm}^{2} / \mathrm{m}^{2}$ vs. $2983(747)$ and $3408(980)$ dynes $/ \mathrm{sec} / \mathrm{cm}^{2} / \mathrm{m}^{2}$ in IH patients $(p=0.002$ post-dialysis). There were between-group differences in TPRI change $(0=0.0001)$, but not $\mathrm{CI}$ $(p=0.09)$. Conclusions: Recurrent intradialytic hypertension is associated with higher postdialysis extracellular volume and TPRI. Intradialytic TPRI surges account for the vasoconstrictive state post-dialysis, but intradialytic fluid shifts may contribute to post-hemodialysis volume expansion.




\section{Kidney Blood Pressure Research}

Kidney Blood Press Res 2016;41:802-814

DOI: 10.1159/000450565

Published online: November 11, 2016

(C) 2016 The Author(s). Published by S. Karger AG, Base

Van Buren et al.: Intradialytic Hypertension: Fluid and Hemodynamics

\section{Introduction}

Individual blood pressure (BP) measurements obtained inside the hemodialysis unit are inferior predictors of mortality for hemodialysis patients compared to averaged measurements obtained outside the unit [1]. There is accumulating evidence that specific BP patterns during dialysis provide additional prognostic information. Both large BP decreases during dialysis and generalized BP variability are associated with increased mortality [24]. However, even subtle BP increases during dialysis have recently been shown to increase mortality risk [5].

Intradialytic hypertension $(\mathrm{IH})$ refers to a $\mathrm{BP}$ increase from pre- to post-dialysis. Most hemodialysis patients experience IH in a small percentage of their dialysis treatments, but IH is a persistent and recurrent phenomenon in some hemodialysis patients [6]. Understanding the pathophysiology of IH is important because patients with recurrent $\mathrm{IH}$ have higher ambulatory BP burden [7, 8] and increased risk for morbidity and mortality [5, 9-11]. A recent cross-sectional study utilizing bioimpedance spectroscopy found that patients with $\mathrm{BP}$ increases during a single hemodialysis treatment were more volume overloaded than patients with BP decreases [12]. Separate studies in patients with recurrent IH have found IH to be associated with dynamic imbalances in vasodilating and vasoconstricting peptides during dialysis as well as increased endothelial cell dysfunction [13-15].

Bioimpedance spectroscopy has never been utilized in patients with recurrent $\mathrm{IH}$, and the relative extracellular volume status of this population remains unknown. Furthermore, no study has simultaneously assessed cardiovascular hemodynamic changes and extracellular volume changes in patients with recurrent IH. These measurements can be obtained with non-invasive equipment at the bedside and provide further insight into the factors responsible for intradialytic BP patterns.

In this study, we sought to directly compare changes in hemodynamics simultaneously with extracellular volume in patients with recurrent IH and other hypertensive hemodialysis controls using non-invasive equipment easily utilized in the hemodialysis unit. We hypothesized that IH patients would be more volume overloaded after dialysis than controls. We also hypothesized that differences in peripheral resistance, but not cardiac output would exist between these two groups.

\section{Materials and Methods}

\section{Design and Subjects}

This case-control study compared patients with recurrent IH and hypertensive hemodialysis controls. Using consecutive sampling, we screened patients from three University-affiliated hemodialysis units by reviewing BP measurements from six prior hemodialysis treatments. Inclusion criteria were age $>18$ years, hemodialysis vintage $>1$ month, and hypertension defined by Kidney Disease Quality Outcomes Initiative guidelines (systolic BP >140 mmHg pre-dialysis or $>130 \mathrm{mmHg}$ post-dialysis) [16]. An additional criterion for case subjects with IH was a systolic BP increase $>10 \mathrm{mmHg}$ from pre- to post-dialysis in $4 / 6$ screening treatments. For controls, an additional inclusion criterion was a systolic BP decrease $>10 \mathrm{mmHg}$ from preto post dialysis in 4/6 screening treatments. Exclusion criteria were major extremity amputation; cardiac defibrillator, pacemaker or coronary artery stent; pregnancy, metal prosthesis, or persistently being above prescribed dry weight.

Subjects signed written, informed consent before procedures. The University of Texas Southwestern Medical Center Institutional Review Board approved the protocol. All procedures were in accordance of the Declaration of Helsinki. The study was part of a clinical trial, NCT01862497 [17].

\section{Study Procedures}

Volume Measurements. Before a mid-week hemodialysis treatment, subjects were weighed on a dialysis-unit scale. We measured body volumes using whole-body multifrequency bioimpedance 


\section{Kidney Blood Pressure Research}

Van Buren et al.: Intradialytic Hypertension: Fluid and Hemodynamics

spectroscopy (Impedimed SFB7). Electrodes were placed on the wrist, hand, foot, and ankle contralateral to the hemodialysis access after five minutes in the supine position. Measurements were repeated 20-30 minutes post-dialysis. This machine measured total body water (TBW) and extracellular water (ECW) within seconds, and we used the average of five measurements. Intracellular water (ICW) was automatically calculated (TBW-ECW).

Impedance Cardiography. We obtained measurements before and 20-30 minutes after the same midweek hemodialysis treatment. Following Impedimed measurements, we placed Non-Invasive Cardiac Output Monitor (NICOM) electrodes on the chest and abdomen. We obtained measurements of cardiac output and brachial artery BP at one minute intervals while the patient was supine. Total peripheral resistance index (TPRI) was calculated from cardiac output and mean arterial pressure (MAP). Thoracic fluid content and stroke volume index (SVI) were also measured.

Blood Pressure. Blood pressure measurements obtained before, after and during the dialysis treatment were obtained with sphygmomanometers attached to the hemodialysis machines that inflated approximately every 30 minutes. After conclusion of the hemodialysis treatment, patients wore a Spacelabs 90207 ambulatory BP monitor until the next treatment. This cuff inflated every 30 minutes during the daytime and hourly at night.

Laboratory Measurements. Before and after dialysis, $10 \mathrm{~mL}$ of blood was collected from the subjects' hemodialysis accesses in EDTA tubes and immediately centrifuged at $3000 \mathrm{rpm}$ for 10 minutes. Plasma was placed in dry ice until transported to a -80 degree Celsius freezer. Endothelin-1 (ET-1) was measured using quantitative sandwich enzyme immunoassay technique with Human Endothelin-1 Immunoassay (Quantiglo). The coefficients of variation are 2.6-3.4\% for intra-assay precision and 4.6-8.9\% for interassay precision. Asymmetric dimethylarginine (ADMA) was measured using competitive enzyme linked immunosorbent assay (Biovendor) with a microtiter plate format. The coefficients of variation are 4.5-7.5\% for intra-assay variation and 8.3-10.3\% for interassay variation. Additional plasma was shipped to Quest Diagnostics for angiotensin II with immunoassay analysis. In samples with remaining plasma, additional analyses were performed for osmolarity using an Advance Osmometer and for individual measurements of sodium with the Ortho Clinical Vitros 250 Chemistry System. Other laboratory measurements were obtained from patient's records.

\section{Statistical Analysis}

Continuous variables were presented as mean and standard deviation for normally distributed variables and median with interquartile range for non-normally distributed variables. Between-group comparisons in categorical variables were made with chi-square analysis or Fishers Exact test for categorical variables and student's t-test for continuous variables. We selected the post-dialysis ECW/TBW ratio as the primary outcome because it signified the volume status of the patient after ultrafiltration had taken place. We also calculated pre- and post-dialysis ECW/body weight for a more robust data analysis that would not be affected by the measurements of intracellular fluid. We used an equation that is validated in other bioimpedance devices to estimate fluid overload before and after dialysis: 1.136 *ECW-0.430*ICW$.114^{*}$ weight $[18,19]$. R-version 3.2 .3 was used for statistical analyses.

\section{Results}

\section{Patient Characteristics}

We enrolled 18 subjects per group. Of the 262 patients screened, 44 were eligible case subjects. Fifteen refused to participate, and 11 had exclusion criteria. Baseline characteristics are in Table 1. One IH patient experienced symptomatic hypoglycemia during hemodialysis and refused further procedures. Between-group differences in baseline serum phosphorus, blood urea nitrogen, calcium, and protein catabolic rate were observed. There were no differences in medications, comorbidities, or dialysis prescription. 


\section{Kidney \\ Blood Pressure Research}

Table 1. Baseline Patient Characteristics

\begin{tabular}{|c|c|c|c|}
\hline Demographic Information and Clinical Data & Control $(\mathrm{n}=18)$ & $\begin{array}{c}\text { Intradialytic } \\
\text { Hypertension }(n=18)\end{array}$ & $\begin{array}{c}\mathrm{p}- \\
\text { value }\end{array}$ \\
\hline Age in years (standard deviation) & $50.6(11.2)$ & $50.1(12.2)$ & 0.9 \\
\hline Male (\%) & $14(78)$ & $12(67)$ & 0.7 \\
\hline Hispanic (\%) & $6(33)$ & $6(33)$ & 0.9 \\
\hline Percent African American (\%) & $10(56)$ & $7(39)$ & 0.5 \\
\hline Patients With Diabetes (\%) & $10(56)$ & $11(61)$ & 0.9 \\
\hline Patients With Coronary Artery Disease (\%) & $3(17)$ & $1(6)$ & 0.3 \\
\hline Patients With Congestive Heart Failure (\%) & $3(17)$ & $2(11)$ & 0.7 \\
\hline Tobacco Use & & & 0.3 \\
\hline Never Smoker (\%) & $8(44)$ & $12(67)$ & \\
\hline Current Smoker: (\%) & 7 (39) & $3(17)$ & \\
\hline Quit Within 10 years: (\%) & $3(17)$ & $2(11)$ & \\
\hline Dialysis Vintage & & & 0.9 \\
\hline Less than 6 months: \% & $3(17)$ & $2(11)$ & \\
\hline 6-12 months: \% & $2(11)$ & $3(17)$ & \\
\hline 12-24 months: $\%$ & $1(6)$ & $2(11)$ & \\
\hline More than 2 years: $\%$ & $10(56)$ & $10(56)$ & \\
\hline Unknown by history & $2(11)$ & $1(6)$ & \\
\hline Hemodialysis Access & & & 0.9 \\
\hline Graft: $(\%)$ & $5(28)$ & $5(28)$ & \\
\hline Fistula: $(\%)$ & $10(56)$ & $10(56)$ & \\
\hline Catheter: (\%) & $3(17)$ & $3(17)$ & \\
\hline Hemodialysis Shift & & & 0.3 \\
\hline $1^{\text {st }}(\%)$ & $4(22)$ & $6(33)$ & \\
\hline $2^{\text {nd }}(\%)$ & $9(50)$ & $5(28)$ & \\
\hline $3^{\text {rd }}(\%)$ & $5(28)$ & $7(39)$ & \\
\hline Estimated Dry Weight in kilograms (standard deviation) & $80.9(17.6)$ & $74.2(16.0)$ & 0.2 \\
\hline Weight Pre-dialysis (kg) & $84.5(18.7)$ & $76.3(16.1)$ & 0.2 \\
\hline Weight Post-dialysis (kg) & $81.5(16.1)$ & $74.0(16.1)$ & 0.2 \\
\hline \multicolumn{4}{|l|}{ Dialysis Prescription } \\
\hline Treatment Time (minutes) & $234(18.5)$ & $232(18.7)$ & 0.7 \\
\hline Blood Flow (mL/min) & $403(32.0)$ & $378(42.8)$ & 0.06 \\
\hline Dialysate Flow (mL/min) & $644(78.3)$ & $672(89.5)$ & 0.3 \\
\hline Dialysate Calcium (mEq/L) ${ }^{1}$ & $2.53(0.1)$ & $2.50(0)$ & 0.3 \\
\hline Dialysate Potassium (mEq/L) ${ }^{2}$ & $2.11(0.3)$ & $2.06(0.2)$ & 0.6 \\
\hline Dialysate Sodium (mEq/L) & $139(0.9)$ & $139(0.9)$ & 0.9 \\
\hline \multicolumn{4}{|l|}{ Laboratory Data } \\
\hline Serum Creatinine $(\mathrm{mg} / \mathrm{dL})^{3}$ & $11.3(2.4)$ & $9.85(2.5)$ & 0.09 \\
\hline $\mathrm{Kt} / \mathrm{V}^{1}$ & $1.50(0.3)$ & $1.55(0.3)$ & 0.6 \\
\hline Hemoglobin $(\mathrm{g} / \mathrm{dL})^{3}$ & $10.7(1.5)$ & $10.5(1.2)$ & 0.7 \\
\hline Serum Albumin $(\mathrm{g} / \mathrm{dL})^{3}$ & $3.78(0.3)$ & $3.90(0.3)$ & 0.2 \\
\hline Parathyroid Hormone $(\mathrm{pg} / \mathrm{mL})^{3}$ & $915(1151)$ & $307(147.7)$ & 0.06 \\
\hline Serum Phosphorus $(\mathrm{mg} / \mathrm{dL})^{3}$ & $6.53(1.7)$ & $4.97(1.4)$ & 0.004 \\
\hline Serum Calcium $(\mathrm{mg} / \mathrm{dL})^{3}$ & $8.94(0.6)$ & $9.41(0.7)$ & 0.04 \\
\hline Serum Potassium $(\mathrm{mmol} / \mathrm{L})^{3}$ & $5.02(0.7)$ & $4.76(0.6)$ & 0.2 \\
\hline Blood Urea Nitrogen ${ }^{3}$ & $60.9(16)$ & $47.1(13.1)$ & 0.008 \\
\hline Protein Catabolic Rate $^{3}$ & $1.13(0.3)$ & $0.92(0.2)$ & 0.03 \\
\hline \multicolumn{4}{|l|}{ Antihypertensive Use } \\
\hline Angiotensin Converting Enzyme Inhibitor (\%) & $4(22)$ & $9(50)$ & 0.2 \\
\hline Angiotensin Receptor Blocker (\%) & $4(22)$ & $3(17)$ & 0.9 \\
\hline Beta Adrenergic Receptor Blocker (\%) & $16(89)$ & $15(83)$ & 0.9 \\
\hline Alpha Adrenergic Receptor Blocker (\%) & $12(67)$ & $12(67)$ & 0.9 \\
\hline Calcium Channel Blocker (\%) & $14(78)$ & $14(78)$ & 0.9 \\
\hline Clonidine $(\%)$ & $3(17)$ & $1(6)$ & 0.6 \\
\hline Hydralazine (\%) & $5(28)$ & $4(22)$ & 0.9 \\
\hline
\end{tabular}




\section{Kidney Blood Pressure Research}

Table 2. Blood Pressure Measurements During 2-Week Screening and During Mid-Week Hemodialysis Treatment (with hemodialysis unit sphygmomanometer and with non-invasive cardiac output monitor)

\begin{tabular}{|c|c|c|c|}
\hline & $\begin{array}{c}\text { Controls } \\
(n=18)\end{array}$ & $\begin{array}{c}\text { Intradialytic } \\
\text { Hypertension } \\
(n=18)\end{array}$ & p-value \\
\hline \multicolumn{4}{|l|}{ Measurements Obtained During 2-week Screening Period } \\
\hline Screening Pre-Dialysis Systolic Blood Pressure (mmHg) & $165(18.4)$ & $141(17.4)$ & 0.0002 \\
\hline Screening Post-Dialysis Systolic Blood Pressure (mmHg) & $138(21.1)$ & $162(16.2)$ & 0.0006 \\
\hline Screening Pre-Dialysis Diastolic Blood Pressure (mmHg) & $92.6(13.4)$ & $76.4(12.5)$ & 0.0006 \\
\hline Screening Post-Dialysis Diastolic Blood Pressure (mmHg) & $80.4(13.8)$ & $83.0(10.5)$ & 0.5 \\
\hline Screening Delta Systolic Blood Pressure (mmHg) & $-27.3(22.7)$ & $+20.3(19.3)$ & $<0.0001$ \\
\hline \multicolumn{4}{|c|}{ Measurements Obtained During Mid-Week Hemodialysis Treatment With Hemodialysis Unit Sphygmomanometer } \\
\hline Pre-Dialysis Systolic Blood Pressure (mmHg) & $164(18.5)$ & $142(18.6)$ & 0.001 \\
\hline Post-Dialysis Systolic Blood Pressure (mmHg) & $133(24.9)$ & $149(20.0)$ & 0.03 \\
\hline Change in Systolic Blood Pressure (mmHg) & $-31.2(30.6)$ & $+6.56(24.4)$ & 0.0003 \\
\hline Lowest Systolic Blood Pressure During Dialysis (mmHg) & $115(18.7)$ & $123(15.0)$ & 0.2 \\
\hline \multicolumn{4}{|c|}{ Measurements Obtained During Mid-Week Hemodialysis Treatment With Non-Invasive Cardiac Monitor } \\
\hline Pre-Dialysis Systolic Blood Pressure (mmHg) & $166(25.3)$ & $144(22.1)$ & 0.01 \\
\hline Post-Dialysis Systolic Blood Pressure (mmHg) & $139(24.8)$ & $161(20.9)$ & 0.008 \\
\hline \multicolumn{4}{|l|}{ Ambulatory Blood Pressure Measurements } \\
\hline Ambulatory Systolic Blood Pressure (mmHg) & $141(13.1)$ & $147(12.8)$ & 0.2 \\
\hline Ambulatory Diastolic Blood Pressure (mmHg) & $82.5(12.0)$ & $79.0(11.0)$ & 0.4 \\
\hline
\end{tabular}

\section{Blood Pressure Measurements}

Mean systolic BP change from pre- to post-dialysis during screening was $-27.3( \pm 22.7)$ and $+20.3( \pm 19.3)$ $\mathrm{mmHg}$ in controls and IH subjects, respectively $\quad(\mathrm{p}<0.0001, \quad$ Table $2)$. During the 6 months prior to enrollment, the mean intradialytic systolic BP change was -20.1 (11.2) $\mathrm{mmHg}$ for controls and +4.2 (11.7) $\mathrm{mmHg}$ for $\mathrm{IH}$ subjects $(\mathrm{p}<0.001)$. During that time period, an intradialytic systolic BP increase $\geq 10$ mmHg occurred in $42.5 \%$ of all the IH subject treatments, but in only $11 \%$ of the controls' treatments $(\mathrm{p}<0.001)$.

During the mid-week hemodialysis treatment, differences were noted in pre-dialysis, post-dialysis, and change in systolic BP between the groups (Table 2). Most IH patients had BP increases (14/18), while controls had decreases (15/18). The systolic

BP measured every 30 minutes during dialysis is shown in Figure 1. The average change in systolic BP from pre- to post-dialysis was $-31.2( \pm 30.6) \mathrm{mmHg}$ in controls and $+6.6( \pm 24.4)$ $\mathrm{mmHg}$ in IH patients $(\mathrm{p}=0.0003)$. The NICOM BP measurements showed similar patterns to those of the hemodialysis unit sphygmomanometers (Table 2). There was a trend for ambulatory systolic BP to be higher in IH patients (Table 2). 


\section{Kidney \\ Blood Pressure Research}

Table 3. Measurements of Body Fluid Using Bioimpedance Spectroscopy and Fluid Changes During Hemodialysis

\begin{tabular}{lccc}
\hline & Controls & $\begin{array}{c}\text { Intradialytic } \\
\text { Hypertension }\end{array}$ & $\begin{array}{c}\text { p- } \\
\text { value }\end{array}$ \\
\hline Prior Interdialytic Weight Gain in kg (n=18 for both groups) & $2.56( \pm 1.4)$ & $2.21( \pm 1.2)$ & 0.4 \\
Percentage of Prior Interdialytic Weight Gain (n=18 for both groups) & $3.11( \pm 1.6)$ & $3.19( \pm 2.0)$ & 0.9 \\
Fluid Removal in L (n=18 for both groups) & $2.93( \pm 1.3)$ & $2.40( \pm 1.1)$ & 0.2 \\
Ultrafiltration Rate in mL/hr/kg (n=18 for both groups) & $8.87( \pm 3.5)$ & $8.42( \pm 4.2)$ & 0.7 \\
Pre Hemodialysis Total Body Water in L1 & $48.2( \pm 11.4)$ & $46.5( \pm 9.6)$ & 0.6 \\
Post-Hemodialysis Total Body Water in L & $45.2( \pm 11.1)$ & $43.6( \pm 9.4)$ & 0.7 \\
Change in Total Body Water in L & $-3.37( \pm 2.3)$ & $-3.00( \pm 2.7)$ & 0.7 \\
Pre Hemodialysis Extracellular Water in L (n=18 for both groups) & $21.6( \pm 4.6)$ & $22.0( \pm 4.6)$ & 0.8 \\
Post-Hemodialysis Extracellular Water in L ${ }^{2}$ & $19.1( \pm 4.1)$ & $20.1( \pm 4.7)$ & 0.5 \\
Change in Extracellular Water in L & $-2.73( \pm 1.3)$ & $-1.84( \pm 1.3)$ & 0.06 \\
Pre Hemodialysis Intracellular Water in L1 & $26.7( \pm 7.9)$ & $24.3( \pm 5.3)$ & 0.3 \\
Post-Hemodialysis Intracellular Water in L2 & $26.1( \pm 7.8)$ & $23.4( \pm 4.9)$ & 0.2 \\
Change in Intracellular Water in L & $-0.69( \pm 2.1)$ & $-1.08(1.9)$ & 0.6 \\
Pre-Hemodialysis Ratio of Extracellular Water to Total Body Water 1 & $0.453( \pm 0.05)$ & $0.478( \pm 0.03)$ & 0.05 \\
Post-Hemodialysis Ratio of Extracellular Water to Total Body Water ${ }^{2}$ & $0.427( \pm 0.04)$ & $0.461( \pm 0.03)$ & 0.01 \\
Change in Ratio of Extracellular Water to Total Body Water & $-0.03( \pm 0.03)$ & $-0.01( \pm 0.02)$ & 0.1 \\
Pre-Hemodialysis Ratio of Extracellular Water to Pre Dialysis Weight & $0.260( \pm 0.04)$ & $0.292( \pm 0.05)$ & 0.04 \\
(n=18 for both groups) & & & \\
Post-Hemodialysis Ratio of Extracellular Water to Post-Dialysis & $0.239( \pm 0.04)$ & $0.271( \pm 0.05)$ & 0.03 \\
Weight ${ }^{2}$ & & & \\
Pre-Dialysis Fluid Overload in L & $3.46( \pm 3.8)$ & $5.98( \pm 3.1)$ & 0.05 \\
Post-Dialysis Fluid Overload in L & $1.22( \pm 3.1)$ & $4.23( \pm 3.1)$ & 0.009 \\
\hline
\end{tabular}

${ }^{1}$ There were $2 \mathrm{IH}$ patients with large discordance between pre- and post-intracellular fluid content such that intracellular and total body water fluid were not included in the final analysis. There was one control without predialysis measurements available. For these data, $n=17$ for controls and $n=16$ for IH patients. ${ }^{2}$ There was one patient in the intradialytic hypertension group who did not complete post-dialysis measurements because he had symptomatic hypoglycemia during the study and did not wish to participate for the remaining measurements ( $n=18$ for controls, $n=15$ for $\mathrm{IH}$ patients)

\section{Volume Measurements}

Both groups had similar interdialytic weight gains prior to the mid-week treatment and similar fluid removal and ultrafiltration rates during the mid-week treatment (Table 3). The pre-dialysis ECW/TBW was $0.453( \pm 0.05)$ in controls and $0.478( \pm 0.03)$ in IH subjects $(\mathrm{p}=0.05)$. The post-dialysis ECW/TBW was $0.427( \pm 0.04)$ in controls and $0.461( \pm 0.03)$ in IH subjects $(\mathrm{p}=0.01)$. The ratios for ECW/body weight were higher in IH subjects than controls both before and after dialysis ( $\mathrm{p}=0.04$ for pre- and $\mathrm{p}=0.03$ for post). For controls, the changes in ECW and ECW/TBW from pre- to post-dialysis were $-2.73 \mathrm{~L}( \pm 1.3)$ and $-0.27 \mathrm{~L}( \pm 0.03)$ compared to $-1.84( \pm 1.3)$ and $-0.13(0.02)$ in IH subjects $(\mathrm{p}=0.06$ and 0.1 , respectively). The TBW change from pre- to post-dialysis was numerically larger in controls than IH subjects $(-3.37 \mathrm{~L}[2.4]$ vs. $-3.00 \mathrm{~L}$ [2.7], $\mathrm{p}=0.6)$, but the ICW change was numerically larger in IH subjects than controls ( $-1.08 \mathrm{~L}$ [1.9] vs. $-0.69 \mathrm{~L}$ [2.1], $\mathrm{p}=0.6)$. Fluid overload, which we defined as $1.134^{*}(\mathrm{ECW})-0.43^{*}(\mathrm{ICW})-0.114^{*}$ weight [18], after dialysis was $1.22 \mathrm{~L}( \pm 3.1)$ in controls and $4.23 \mathrm{~L}( \pm 3.1)$ in IH subjects $(\mathrm{p}=0.009)$. The difference between intended ultrafiltration (pre-dialysis weight minus estimated dry weight) and achieved ultrafiltration was $0.65 \mathrm{~L}$ (1.2) in controls and $-0.24 \mathrm{~L}(0.5)$ in IH subjects ( $\mathrm{p}=0.009)$.

\section{Impedance Cardiography and Biochemical Measurements}

Measurements of individual pre- and post-dialysis hemodynamics obtained with impedance cardiography are in Table 4. The TPRI decreased from $3254( \pm 994)$ to $2469( \pm 529)$ dy$\mathrm{nes} / \mathrm{sec} / \mathrm{cm}^{2} / \mathrm{m}^{2}$ from pre- to post-dialysis in controls, and it increased from $2983( \pm 747)$ to $3408( \pm 980)$ dynes $/ \mathrm{sec} / \mathrm{cm}^{2} / \mathrm{m}^{2}$ in IH subjects ( $\mathrm{p}=0.4,0.002$, and 0.0001 for between-group pre-, post- and delta comparisons). This was concordant with MAP decrease from 118 


\section{Kidney \\ Blood Pressure Research}

Table 4. Pre- and Post-Dialysis Impedance Cardiography (Non-Invasive Cardiac Output Monitor) and Biochemical Measurements

\begin{tabular}{|c|c|c|c|}
\hline & $\begin{array}{c}\text { Controls } \\
(\mathrm{n}=18)\end{array}$ & $\begin{array}{c}\text { Intradialytic } \\
\text { Hypertension } \\
(\mathrm{n}=18)\end{array}$ & p-value \\
\hline Pre-Dialysis Cardiac Index $\left(\mathrm{L} / \mathrm{min} / \mathrm{m}^{2}\right)$ & $3.08(0.7)$ & $2.77(0.5)$ & 0.2 \\
\hline Post-Dialysis Cardiac Index $\left(\mathrm{L} / \mathrm{min} / \mathrm{m}^{2}\right)$ & $3.34(0.5)$ & $2.72(0.6)$ & 0.002 \\
\hline Pre-Dialysis Heart Rate (beats per min) & $76.0(10.9)$ & $70.7(10.7)$ & 0.1 \\
\hline Post-Dialysis Heart Rate (beats per min) & $84.4(14.1)$ & $72.7(8.8)$ & 0.006 \\
\hline Pre-Dialysis Mean Arterial Pressure (mmHg) & $118(14.3)$ & $99.2(13.7)$ & 0.0003 \\
\hline Post-Dialysis Mean Arterial Pressure (mmHg) & $101(15.4)$ & $110(13.8)$ & 0.09 \\
\hline $\begin{array}{l}\text { Pre-Dialysis Total Peripheral Resistance Index } \\
\left(\text { dynes } / \mathrm{sec} / \mathrm{cm}^{2} / \mathrm{m}^{2} \text { ) }\right.\end{array}$ & $3254(994)$ & $2983(747)$ & 0.4 \\
\hline $\begin{array}{l}\text { Post-Dialysis Total Peripheral Resistance Index } \\
\left(\text { dynes } / \mathrm{sec} / \mathrm{cm}^{2} / \mathrm{m}^{2}\right)\end{array}$ & $2469(529)$ & $3408(980)$ & 0.002 \\
\hline Pre-Dialysis Stroke Volume Index $\left(\mathrm{mL} /\right.$ beat $\left./ \mathrm{m}^{2}\right)$ & $41.0(9.7)$ & $39.9(9.3)$ & 0.7 \\
\hline Post-Dialysis Stroke Volume Index (mL/beat/m²) & $40.4(7.9)$ & $37.4(7.5)$ & 0.3 \\
\hline Pre-DialysisThoracic Fluid Content $\left(\mathrm{k} \Omega^{-1}\right)$ & $46.7(12.4)$ & $49.0(11.8)$ & 0.6 \\
\hline Post-DialysisThoracic Fluid Content $\left(\mathrm{k} \Omega^{-1}\right)$ & $39.6(10.0)$ & $46.6(14.8)$ & 0.1 \\
\hline Pre-Dialysis Endothelin-1 (pg/mL) ${ }^{1}$ & $1.9(0.6)$ & $2.1(1.1)$ & 0.5 \\
\hline Post-Dialysis Endothelin-1 (pg/mL) ${ }^{1}$ & $2.05(0.6)$ & $2.18(1.0)$ & 0.7 \\
\hline Pre-Dialysis Asymmetric Dimethylarginine $(\mu \mathrm{mol} / \mathrm{L})^{1}$ & $0.80(0.2)$ & $0.70(0.1)$ & 0.1 \\
\hline Post-Dialysis Asymmetric Dimethylarginine $(\mu \mathrm{mol} / \mathrm{L})^{1}$ & $0.56(0.2)$ & $0.39(0.08)$ & 0.001 \\
\hline Pre-Dialysis Angiotensin II ${ }^{1,2}(\mathrm{ng} / \mathrm{L})$ & $22.4(16.3)$ & $18.9(6.3)$ & 0.5 \\
\hline Post-Dialysis Angiotensin II $1{ }^{1,2}(\mathrm{ng} / \mathrm{L})$ & $23.2(8.2)$ & $23.6(15.0)$ & 0.9 \\
\hline
\end{tabular}

$( \pm 14.3)$ to $101( \pm 15.4) \mathrm{mmHg}$ in controls and increases from $99.2( \pm 13.7)$ to $110( \pm 13.8)$ $\mathrm{mmHg}$ in IH subjects ( $\mathrm{p}=0.003,0.09$, and 0.00001 for between group difference in pre-, post and delta comparisons). There was no difference in the change in CI (0.09) or SVI ( $p=0.6)$. Figure 2 depicts the pre- to post-dialysis changes in MAP, CI, SVI, heart rate, and TPRI. There were no differences in the changes in ET-1 $(p=0.6)$, ADMA $(p=0.3)$ between groups.

\section{Osmolarity and Sodium Measurements}

In a subset of patients with available data, the pre-HD, post-HD, and change in plasma osmolarity were $320( \pm 5.98), 299( \pm 3.32)$, and $-20.9 \mathrm{mOsm} / \mathrm{kg}( \pm 5.33)$ in the controls $(\mathrm{n}=9)$ and $315( \pm 4.49), 302( \pm 8.96)$, and $-12.8 \mathrm{mOsm} / \mathrm{kg}( \pm 10.20)$ in the IH subjects $(\mathrm{n}=10)$ $(\mathrm{p}=0.07,0.3$, and 0.04$)$. In the same subgroup, the plasma sodium and plasma to dialysate sodium gradient were $136( \pm 5.78)$ and $-2.4 \mathrm{mmol} / \mathrm{L}(5.78)$ in controls and $138( \pm 5.06)$ and $-0.25 \mathrm{mmol} / \mathrm{L}( \pm 5.06)$ in IH patients $(\mathrm{p}=0.4$ and 0.4$)$. Serum chemistry data that significantly deviated from physiologic range ( $n=1$ for pre dialysis sodium; $n=3$ for post dialysis sodium) were not analyzed. Complete data are in Table 5.

\section{Discussion}

The principal new findings of this study are that patients with recurrent IH have both elevated post-dialysis extracellular volume relative to TBW and elevated post-dialysis TPRI compared to hypertensive hemodialysis controls. Intradialytic TPRI surges occurred in IH patients, but increases in commonly known circulating vasoconstrictors were not observed. Our findings are unique in that they 1) were found in patients with persistent and recurrent IH based on rigorous screening methodology; 2) simultaneously combine components of hemodynamics and body volume measurements using non-invasive equipment that can be readily used in the dialysis unit; and 3) explore changes in intradialytic fluid distribution.

Post-dialysis ECW/TBW was higher in patients with recurrent IH compared to controls despite similar interdialytic weight gain, intradialytic fluid removal, and ultrafiltration 


\section{Kidney \\ Blood Pressure \\ Research}

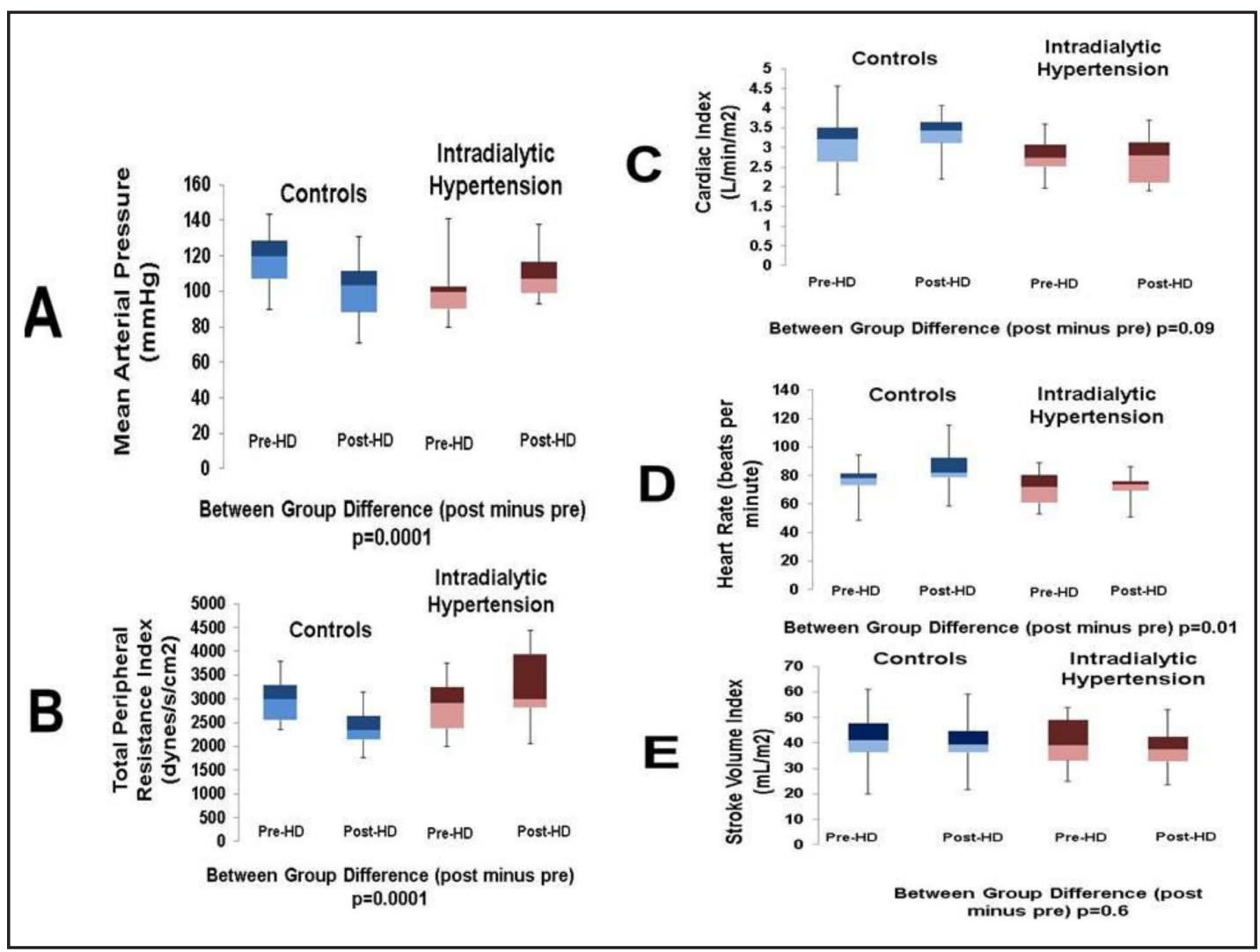

Fig. 2. shows the changes in various measurements obtained with impedance cardiography from pre to post-dialysis. The mean arterial pressure (A) increased in the IH patients and decreased in controls. While there was no difference in the change in cardiac index $(\mathrm{C})$ between the groups from pre- to post-dialysis, there was an increase in total peripheral resistance index(B) in the IH patients and a decrease in controls. In considering the individual components of the cardiac index, there was a larger increase in heart rate in controls (D), but no difference in the change in stroke volume index (E) between the two groups. The data is presented in box-whisker plots to indicate maximum, minimum, $25^{\text {th }}, 50^{\text {th }}$, and $75^{\text {th }}$ percentiles.

Table 5. Comparison of Pre-Dialysis, Post-Dialysis, and Changes From Pre to Post Dialysis in Osmolarity and Plasma Sodium

\begin{tabular}{lccc}
\hline & Control & $\begin{array}{c}\text { Intradialytic } \\
\text { Hypertension }\end{array}$ & $\begin{array}{c}\mathrm{p} \text { - } \\
\text { value }\end{array}$ \\
\hline Pre-Dialysis Plasma Osmolarity (m0sm/kg) & $320( \pm 5.98) ; \mathrm{n}=9$ & $315( \pm 4.49) ; \mathrm{n}=10$ & 0.07 \\
Post-Dialysis Plasma Osmolarity (m0sm/kg) & $299( \pm 3.32) ; \mathrm{n}=9$ & $302( \pm 8.96) ; \mathrm{n}=10$ & 0.3 \\
Change in Plasma Osmolarity from pre to post dialysis (m0sm/kg) & $-20.9( \pm 5.33) ; \mathrm{n}=9$ & $-12.8( \pm 10.2) ; \mathrm{n}=10$ & 0.04 \\
Pre-Dialysis Plasma Sodium (mmol/L) & $136( \pm 5.78) ; \mathrm{n}=10$ & $138( \pm 5.06) ; \mathrm{n}=8$ & 0.4 \\
Post-Dialysis Plasma Sodium (mmol/L) & $137( \pm 5.88) ; \mathrm{n}=9$ & $135( \pm 4.27) ; \mathrm{n}=8$ & 0.4 \\
Dialysate Sodium (mmol/L) & $138( \pm 0) ; \mathrm{n}=11$ & $138( \pm 0) ; \mathrm{n}=10$ & 0.9 \\
Pre-Dialysis Plasma-Dialysate Sodium Gradient (mmol/L) & $-2.4( \pm 5.78) ; \mathrm{n}=10$ & $-0.25( \pm 5.06) ; \mathrm{n}=8$ & 0.4 \\
Change in Plasma Sodium From Pre to Post-Dialysis (mmol/L) & $0.67( \pm 3.36) ; \mathrm{n}=9$ & $-1.71( \pm 5.8) ; \mathrm{n}=7$ & 0.4 \\
\hline
\end{tabular}

rates. This indicates that, independent of relative acute extracellular volume expansion during the interdialytic time period, patients with recurrent IH are chronically extracellular volume overloaded. We chose ECW/TBW as the primary outcome because we were most interested in comparing volume status after ultrafiltration had occurred. These results 


\section{Kidney Blood Pressure Research}

Kidney Blood Press Res 2016;41:802-814

DOI: 10.1159/000450565

Published online: November 11, 2016

(C) 2016 The Author(s). Published by S. Karger AG, Base

www.karger.com/kbr

Van Buren et al.: Intradialytic Hypertension: Fluid and Hemodynamics

were supported by the between-group differences in post-dialysis ECW/body weight. Our estimate of absolute fluid overload, a metric more appropriate for clinical practice, was also higher after dialysis in IH subjects compared to controls. The difference in intended and achieved ultrafiltration was very small in IH subjects. This indicates that the IH patients' residual extracellular volume overload was not related to unattainable ultrafiltration goals from excessive weight gain or intradialytic hypotension, but more likely to underestimation of dry weight. Our overall conclusion using multiple assessments of post-dialysis volume is that patients with recurrent IH have more chronic extracellular volume overload compared to controls.

Our data adds to prior evidence that intradialytic BP patterns provide insight into chronic extracellular volume status. The Dry Weight Intervention Trial In Hypertensive Hemodialysis Patients (DRIP) trial showed that intradialytic BP slopes in hypertensive hemodialysis patients were steepened by dry weight reduction [20]. In a more recent cross sectional study, Nongnuch et al. used bioimpedance to measure fluid volumes before and after a single hemodialysis treatment in 531 patients and found ECW/TBW was highest in patients with increases in BP during dialysis [12].

The broader patient demographic included in the DRIP trial limits direct extrapolation to patients with recurrent IH. Similarly, the Nongnuch study defined IH based on BP changes during a single hemodialysis treatment. Our study was specific to patients with recurrent IH due to our case-control designation being determined by BP patterns observed over a 2-week screening period. Furthermore, our study demonstrated that our groups had significantly different BP patterns throughout the prior 6 months. This is a critical distinction given the amount of intertreatment BP variability in hemodialysis patients. We previously showed that an increase in systolic BP $\geq 10 \mathrm{mmHg}$ from pre- to post-dialysis occurred at least once in almost all patients in a 350 patient cohort followed for six months, and we have also defined the expected frequency for IH to occur within a dialysis population [6]. Our IH patients in this study (systolic BP increase of at least $10 \mathrm{mmHg}$ from pre- to posthemodialysis in $>40 \%$ of treatments over prior 6 months) experienced IH as frequently as the $80^{\text {th }}-90^{\text {th }}$ percentile from our prior study [6]; and our controls in this study (systolic BP increase of at least $10 \mathrm{mmHg}$ from pre- to post-hemodialysis in $11 \%$ of treatments over prior 6 months) experienced IH as frequently as the $25^{\text {th }}-30^{\text {th }}$ percentile from our prior study [6]. Our current study's methodology clearly minimizes the risk of misclassification bias and is highly applicable to patients with recurrent $\mathrm{IH}$. Our findings support an approach of more aggressive fluid removal as a strategy to manage IH. However, it is unclear what specific changes to a dialysis prescription are necessary to best achieve this goal. In most HD patients, intradialytic blood pressure patterns are related to both chronic extracellular volume overload and as well as acute volume expansion from interdialytic weight gain and the ensuing ultrafiltration rate $[12,21,22]$. The ultrafiltration rates were similar between the two groups in our study, so it is likely that an increase in UF rate (more ultrafiltration over same period of time) may achieve improved volume status and intradialytic hemodynamics in IH patients. It is not clear whether a more preferable approach would be more frequent or longer HD treatments. The most recent randomized clinical trials show benefits of increasing overall weekly dialysis time on the outcomes of BP and left ventricular mass [23, 24]. While the intradialytic BP patterns were not analyzed in these studies, more frequent HD was associated with lower pre-HD systolic BP (nocturnal and daily), lower post-HD systolic BP (nocturnal and daily), lower interdialytic weight gain (nocturnal and daily) and lower ultrafiltration rate (nocturnal) [25]. The patients with more frequent hemodialysis overall had reductions in extracellular water, but not weight due to presumed increase in adiposity over time [26], Such approaches have never been studied specifically in patients with IH, so there is no clear evidence on how dialysis time should be approached in these patients. However, the ability to maintain lower extracellular water after one year is an important component to consider in IH patient presumed to be volume overloaded. 


\section{Kidney Blood Pressure Research}

We additionally found between-group differences in post-dialysis TPRI and TPRI changes from pre- to post-dialysis. The changes in SVI and CI were not different between groups. These findings are consistent with those from another case-control study which used echocardiography to estimate peripheral resistance [13], challenging earlier studies that suggested IH was mediated by volume-induced increases in cardiac output in volumeoverloaded patients [27, 28]. Similar to our prior work [15], we found no between-group difference in the change in ET-1. This remains in contrast to findings of others where postHD ET-1 is higher in IH patients [14, 29]. We also found no between-group differences in the change in ADMA or Angiotensin II. The discrepancy remains unexplained, but in our study we are unable to attribute an increase in either BP or TPRI to any measured vasoconstrictors. The uncontrolled design of our prior pilot study demonstrating improvement in IH with carvedilol limits the ability to confirm whether that effect was due to blunting of ET-1 during dialysis or suppression of sympathetic tone [30].

The mechanism of rise in TPRI in the IH group is unknown. Sympathetic overactivation remains a possible explanation, but alpha and beta adrenergic receptor antagonists were prescribed similarly in both groups. We considered whether acute changes in intravascular volume related to excessive refilling were associated with TPRI changes. Gradual volume expansion in anephric hemodialysis patients increases BP through a delayed increase in vascular resistance, but it is unclear how acute changes in intravascular volume influence vascular resistance in patients with different degrees of chronic overload at baseline. Further mechanistic studies incorporating simultaneous measurements of BP, intravascular blood volume, and peripheral resistance would be necessary to fully uncover the physiologic principles.

One final observation was a trend for the change in ECW and ECW/TBW from preto post-dialysis to be smaller in IH patients. Consistent with the other findings [31], we found that intradialytic ICW change was smaller than ECW change in both groups; but ICW change was numerically larger in IH patients than controls. We considered the possibility that IH patients with greater extracellular volume had more rapid intravascular refill from the interstitial compartment, creating an osmotic gradient that facilitates fluid shifts from the intracellular space to the interstitial space to explain the greater ICW reduction with preservation of ECW. Supporting this, there is observational evidence from the HEMO study that higher post-dialysis BP is associated with smaller reduction in estimated plasma volume [32] In a subgroup of patients in our study with plasma osmolarity measurements, the reduction in osmolarity from pre to post HD was more pronounced in the controls. It is possible that the more stable extracellular osmolarity in IH patients minimized movement of fluid into cells during dialysis that were driven by osmotic gradients and led to more overall ICW reduction resulting from ultrafiltration. Importantly, a large plasma-to-dialysate sodium gradient (dialysate sodium higher than plasma) is another proposed etiology of $\mathrm{IH}$, in general. One small cross-over study showed that low dialysate sodium in IH patients causes intradialytic BP decreases compared to higher dialysate sodium [33]. In the subgroup of our patients in this study with available data, there was no significant difference in pre-HD sodium, dialysate sodium, or the gradient between plasma and dialysate between the two groups. The limited sample size prevents any definitive conclusions to be made from these results, but the dialysate-to-serum sodium gradient should be monitored. Further studies differentiating intravascular from interstitial fluid shifts are required to examine how BP and peripheral resistance change in the course of a dialysis treatment.

Limitations include using cardiac output and fluid measurements that are not gold standard. However, the NICOM has been validated for cardiac output in hemodialysis and heart failure patients [34, 35], and the Impedimed has been used extensively for measuring body composition and fluid status in hemodialysis patients $[19,36]$. Importantly, both devices are mobile and easily used at the bedside. Right heart catheterizations or dilutions studies would not have been feasible for the purpose of this research to obtain gold standard 


\section{Kidney \\ Blood Pressure Research}

measurements. We acknowledge that with multifrequency bioimpedance spectroscopy the TBW measurements are more prone to procedural error than ECW measurements. There were $2 \mathrm{IH}$ patients with unexplainable changes in TBW and ICW $(>10 \mathrm{~L}$ increase from pre- to post-HD) that were considered physiologically impossible, and these data were excluded from the primary analysis. However, inclusion of these data would not have drastically impacted the results ( $\mathrm{p}=0.06$ for ECW/TBW analysis), and our findings with the ECW/body weight and fluid overload comparisons in all subjects support our findings. We also acknowledge that we did not have complete data on plasma sodium (and hence plasma to dialysate sodium gradient) in all our subjects. Our data showed no difference in these measurements between groups, but this could be due to the smaller number of subjects with available data. Finally, our study was observational. While we rigorously obtained measurements, we cannot attribute causality of our findings to the occurrence of IH, particularly in the context of a relatively small sample size with multiple comparisons. We do not have documentation of interventions made during the HD treatments, but it is unlikely that any undocumented increases in ECW/TBW from fluid boluses for intradialytic hypotension in controls would have changed our conclusions as it would have driven the results more towards the null hypothesis.

\section{Conclusion}

We found that patients with recurrent IH were more volume overloaded after dialysis and had more vasoconstriction related to peripheral resistance surges compared to hemodialysis controls. In the IH patients, there were intradialytic compartmental changes in volume favoring a preservation of fluid in the extracellular space that contributes to postdialysis extracellular volume overload. Changes in plasma vasoconstrictors failed to explain the differences in total peripheral resistance. This study supports consideration of dry weight probing in patients with IH as the initial management. The simultaneous increases in vascular resistance, independent of vasoconstrictor levels, warrant further investigation into the mechanistic relationship between acute changes in fluid balance and BP.

\section{Disclosure Statement}

The primary results of this manuscript have not been published in part or in whole previously. The results will be presented as a poster abstract at the American Society of Nephrology Annual Meeting in November 2016 (Chicago, Illinois).

\section{Acknowledgements}

Support for this study comes from NIH 1K23DK096007-01A1 Patient Oriented Career Development Award (PVB) and institutional support as the Dedman Family Scholar in Clinical Care (PVB). JAN has been supported by the Ben J. Lipps Research Fellowship Program of the American Society of Nephrology Foundation for Kidney Research and the Truelson Fellowship Fund at UT Southwestern Charles and Jane Pak Center of Mineral Metabolism and Clinical Research. Research in this study was further supported by the National Center for Advancing Translational Sciences of the National Institute of Health under award number UL1TR001105 and the University of Texas Southwestern O'Brien Kidney Research Core (National Institutes of Health [NIH] grant P30DK079328). The content is solely the responsibility of the authors and does not necessarily represent the official views of the NIH. 


\section{Kidney \\ Blood Pressure Research} \begin{tabular}{l} 
Kidney Blood Press Res 2016;41:802-814 \\
\begin{tabular}{l|l}
\hline DOI: $10.1159 / 000450565$ & C 2016 The Author(s). Published by S. Karger AG, Basel \\
Published online: November 11, 2016 & www.karger.com/kbr
\end{tabular} \\
\hline
\end{tabular}

\section{References}

1 Alborzi P, Patel N, Agarwal R: Home blood pressures are of greater prognostic value than hemodialysis unit recordings. Clin J Am Soc Nephrol 2007;2:1228-1234.

2 Chang T, Flythe J, Brunelli S, Muntner P, Greene T, Cheung A, Chertow G: Visit-to-visit systolic blood pressure variability and outcomes in hemodialysis. J Hum Hypertens 2014;28:18-24.

3 Flythe J, Inrig J, Shafi T, Chang T, Cape K, Dinesh K, Kunaparaju S, Brunelli S: Intradialytic Blood Pressure Variability is Associated With Increased All-Cause and Cardiovascular Mortality in Patients Treated With Long-term Hemodialysis. Am J Kidney Dis 2013;61:966-974.

4 Shoji T, Tsubakihara Y, Fujii M, Imai E: Hemodialysis-associated hypotension as an independent risk factor for two-year mortality in hemodialysis patients. Kidney Int 2004;66:1212-1220.

5 Park J, Rhee C, Sim J, KIm Y, Ricks J, Streja E, Vashistha T, Tolouian R, Kovesdy C, Kalantar-Zadeh K: A comparative effectiveness research study of the change in blood pressure during hemodialysis treatment and survival. Kidney Int 2013;84:795-802.

6 Van Buren P, Kim C, Toto R, Inrig J: The prevalence of persistent intradialytic hypertension in a hemodialysis population with extended follow-up. Int J Artif Organs 2012;35:1031-1038.

7 Van Buren P, Kim C, Toto R, Inrig J: Intradialytic Hypertension and the association with interdialytic ambulatory blood pressure. Clin J Am Soc Nephrol 2011;6:1684-1691.

8 Hompesch C, Ma T, Neyra J, Ripley L, Xiao G, Inrig J, Toto R, Van Buren P: Comparison of Ambulatory Blood Pressure Patterns in Patients With Intradialytic Hypertension and Hemodialysis Controls. Kidney Blood Press Res 2016;41:240-249.

9 Inrig J, Oddone E, Hasselbad V, Gillespie B, Patel U, Reddan D, Toto R, Himmelfarb J, Winchester J, Stivelman J, Lindsay R, Szczech L: Association of intradialytic blood pressure changes with hospitalization and mortality rates in prevalent ESRD patients. Kidney Int 2007;71:454-461.

10 Inrig J, Patel U, Toto R, Szczech L: Association of blood pressure increases during hemodialysis with 2-year mortality in incident hemodialysis patients: a secondary analysis of the Dialysis Morbidity and Mortality Wave 2 Study. Am J Kidney Dis 2009;54:881-890.

11 Losito A, Del Vecchio L, Del Rosso G, Locatelli F: Postdialysis Hypertension: Associated Factors, Patient Profiles, and Cardiovascular Mortality. Am J Hypertens 2016;29:684-689.

12 Nongnuch A, Campbell N, Stern E, El-Kateb S, Fuentes L, Davenport A: Increased postdialysis systolic blood pressure is associated with extracellular overhydration in hemodialysis outpatients. Kidney Int 2015;87:452-457.

13 Chou K, Lee P, Chen C, Chiou C, Hsu C, Chung H, Liu C, Fang H: Physiologic changes during hemodialysis in patients with intradialysis hypertension. Kidney Int 2006;69:1833-1838.

14 Raj D, Vincent B, Simpson K, Sato E, Jones K, Welbourne T, Levi M, Shah V, Blandon P, Zager P, Robbins R: Hemodynamic changes during hemodialysis: Role of nitric oxide and endothelin. Kidney Int 2002;61:697704.

15 Inrig J, Van Buren P, Kim C, Vongpatanasin W, Povsic T, Toto R: Intradialytic Hypertension and its Association wtih Endothelial Cell Dysfunction. Clin J Am Soc Nephrol 2011;6:2016-2024.

16 Foundation NK: K/DOQI Clinical Practice Guidelines for Cardiovascular Disease in Dialysis Patients. Am J Kidney Dis Suppl 2005;45:S1-S154.

17 With Intradialytic Hypertension. In: ClinicalTrials.gov [Internet]. Bethesda (MD): National Library of Medicine (US). 2000-[cited January 16, 2016] Available from https://www.clinicaltrials. gov/ct2/show/NCT01862497?term=van+buren\&rank=2; NLM identifier NCT01862497 NIoDaDaKDNTUoTSMCaDMaToIABPiP.

18 Abbas S, Zhu F, Levin N: Bioimpedance Can Solve Problems of Fluid Overload. J Ren Nutr 2015;25:234-237.

19 Abreo A, Chertow G, Dalrymple L, Kaysen G, Johansen K: Association of bioimpedance spectroscopybased volume estimation with postdialysis hypotension in patients receiving hemodialysis. Hemodial Int 2015;19:536-542.

20 Agarwal R, Light R: Intradialytic hypertension is a marker of volume excess. Nephrol Dial Transplant 2010;25:3355-3361. 


\section{Kidney \\ Blood Pressure Research}

21 Inrig J, Patel U, Gillespie B, Hasselbad V, Himmelfarb J, Reddan D, Lindsay R, Winchester J, Stivelman J, Toto R, Szczech L: Relationship between interdialytic weight gain and blood pressure among prevalent hemodialysis patients. Am J Kidney Dis 2007;2007:108-118.

22 Dinesh K, Kunaparaju S, Cape K, Flythe J, Feldman H, Brunelli S: A model of systolic blood pressure during the course of dialysis and clinical factors associated with various blood pressure behaviors. Am J Kidney Dis 2011;58:794-803.

23 Rocco M, Lockridge R, Beck G, Eggers P, Gassman J, Greene T, Larive B, Chan C, Chertow G, Copland M, Hoy C, Lindsay R, Levin N, Ornt D, Pierratos A, Pipkin M, Rajagopalan S, Stokes J, Unruh M, Star R, Kliger A: The effects of frequent nocturnal home hemodialysis: the Frequent Hemodialysis Network Nocturnal Trial. Kidney Int 2011;80:1080-1091.

24 Group TFT: In-Center Hemodialysis Six Times per Week versus Three Times per Week. N Engl J Med 2010;363:2287-2300.

25 Kotanko P, Garg A, Depner T, Pierratos A, Chan C, Levin N, Greene T, Larive B, Beck G, Gassman J, Kliger A, Stokes J: Effects of Frequent Hemodialysis on Blood Pressure: Results from the Randomized Frequent Hemodialysis Network Trials. Hemodial Int 2015;19:386-401.

26 Kaysen G, Greene T, Larive B, Mehta R, Lindsay R, Depner T, Hall Y, Daugirdas J, Chertow G: The Effect of Frequent Hemodialysis on Nutrition and Body Composition: Frequent Hemodialysis Network Trial. Kidney Int 2012;82:90-99.

27 Gunal A, Karaca I, Celiker H, Ilkay E, Duman S: Paradoxical rise in blood pressure during ultrafiltration is caused by increased cardiac output. J Nephrol 2002;15:42-47.

28 Cirit M, Akcicek F, Terzioglu E, Soydas C, Ok E, Ozbasli C, Basci A, Mees E: "Paradoxical" rise in blood pressure during ultrafiltration in dialysis patients. Nephrol Dial Transplant 1995;10:1417-1420.

29 El-Shafey E, El-Nagar G, Selim M, El-Sorogy H, Sabry A: Is there a role for endothelin-1 in the hemodynamic changes during hemodialysis? Clin Exp Nephrol 2008;2008:370-375.

30 Inrig J, Van BUren P, Kim C, Vongpatanasin W, Povsic T, Toto R: Probing the Mechanisms of Intradialytic Hypertension: A Pilot Study Targeting Endothelial Cell Dysfunction. Clin J Am Soc Nephrol 2012;7:13001309.

31 Jeong H, Lim C, Choi H, Oh DJ: The source of net ultrafiltration during hemodialysis is mostly the extracellular space regardless of hydration status. Hemodial Int 2016;20:129-133.

32 Leypoldt J, Cheung A, Delmez J, Gassman J, Levin N, Lewis J, Lewis J, Rocco M: Relationship between volume status and blood pressure during chronic hemodialysis. Kidney Int 2002;61:266-275.

33 Inrig J, Molina C, D'Silva K, Kim C, Van Buren P, Allen J, Toto R: Effect of low versus high dialysate sodium concentration on blood pressure and endothelial-derived vasoregulators during hemodialysis: a randomized crossover study. Am J Kidney Dis 2015;65:464-473.

34 Squara P, Denjean D, Estagnasie P, Brusset A, Dib J, Dubois C: Noninvasive cardiac output monitoring (NICOM): a clinical validation. Intensive Care Med 2007;33:1191-1194.

35 Kossari N, Hufnagel G, Squara P: Bioreactance: A new tool for cardiac output and thoracic fluid content monitoring during hemodialysis. Hemodial Int 2009;13:512-517.

36 Johansen K, Dalrymple L, Delgado C, Kaysen G, Kornak J, Grimes B, Chertow G: Association between Body Composition and Frailty among Prevalent Hemodialysis Patients: A US Renal Data System Special Study. J Am Soc Nephrol 2014;25:381-389. 